\title{
The use of maternal health services in Nigeria: does ethnicity and religious beliefs matter?
}

\begin{abstract}
The social environment is known to influence our attitudes and behavior in all spheres of life including the utilization of maternal health services (MHS). This study was aimed to determine whether Nigerian women's cultural profile measured by ethnicity and religious beliefs is significantly associated with the use of antenatal care (ANC) and delivery services. A secondary data analysis of the Nigerian Demographic and Health Survey (DHS) was used to explore whether the ethnicity and religious affiliations of women influence the use of ANC and delivery services. A total of 33,385 women (15-49years) were randomly selected using a stratified two stage cluster sampling from 286 and 602 urban and rural clusters respectively from the 36 states and the Federal Capital Territory (FCT) proportionate to population size of each cluster. Christians have higher proportion of women that had 4 or more ANC visits $(28.2 \%)$ compared to women belonging to Islamic faith $(21.6 \%)$. A woman's religious beliefs was found to be statistically associated with the number of ANC visits $\left(\chi^{2}=189.956 \mathrm{df}=2 ; p<.001\right)$. Christian women are more likely to have 4 or more ANC visits than their Muslim counterparts (AOR=1.172; CI $1.158-1.983 ; p<.001)$. Christian women are mores 5 times more likely to deliver in a health facility than their Muslim counterparts $(\mathrm{UOR}=5.181$; CI 4.844 - 5.542). However, after adjusting for confounding, this association was no longer statistically significant (AOR=1.308; CI 0.987-1.733; $p>.05$ ). The odds of a Yoruba woman (South west) giving birth in a health facility is 35 folds compared to a Hausa woman (UOR=34.817; CI 30.233-40.097), followed by Igala in the North central (UOR=29.723; CI 21.509-41.076) and Igbo in the south east (UOR=26.562; CI 23.035-30.63) This association remained statistically significant even after controlling for confounding. This study ethnicity and religious beliefs to a lesser extent have influenced the use of ANC and delivery services in Nigeria. Policy makers should consider systematic and deliberate involvement of tribal and religious leaders when formulating strategies to reach ethnic nationalities.
\end{abstract}

Keywords: ethnicity, religious beliefs, utilization, antenatal, delivery services
Volume 6 Issue $6-2017$

\author{
Abubakar Sadiq Umar \\ School of Public Health, Walden University, USA
}

Correspondence: Abubakar Sadiq Umar, School of Public Health, College of Health Sciences, Walden University, 100 Washington Avenue, South, Minneapolis, MN 5540I, USA, Tel +263-785467I72, Email abubakar.umar@waldenu.edu

Received: November 16, 2017 | Published: December II, 2017

\section{Introduction}

Although there has been significant reduction in the total number of maternal deaths worldwide, however, many developing countries like Nigeria have not been able to achieve MDG 5 by the end of 2015 . This is buttressed by the fact that Nigeria and India recorded 58,000 $(19 \%)$ and $45,000(15 \%)$ maternal deaths respectively accounting for $34 \%$ of the total global maternal deaths. ${ }^{1}$ Moreover, $59 \%$ of maternal deaths occurred in six Africa Countries (Democratic Republic of Congo, Ethiopia, Kenya, Nigeria, Tanzania and Uganda) and four Asian countries (Bangladesh, India, Indonesia, and Pakistan). ${ }^{2}$

The high number of maternal deaths in Nigeria may partially be due to low use of MHS. ${ }^{3}$ nearly half of the estimated 8.3 million pregnant women in 2010 had no antenatal care. Moreover, among those that had reported to have had antenatal care (ANC), only 55\% of them had made four or more ANC visits before delivery. ${ }^{3}$ fewer proportions $(38 \%)$ of deliveries were attended by skilled health workers in Nigeria. ${ }^{3}$ The Demographic and Health Survey (DHS) estimated a maternal mortality ratio of 545 per 100,000 live births, with the true values likely ranging from 475 deaths in the southwestern zones to 615 deaths in the north-eastern zone per 100,000 live births. ${ }^{4}$ This is an underestimation compared with the reported 630 per 100,000 live births ${ }^{3}$ and might be due to low sensitivity of maternal death surveillance ${ }^{5}$ and poor record keeping of vital events such as births and deaths. ${ }^{6}$ Women living in the Northern regions of Nigeria have the highest risk of dying from pregnancy and delivery complications compared with women residing in other regions of the country. ${ }^{4}$ These national level performances does not reflect the significant disparities that exist between the various geopolitical zones that have predominant ethnic group and in most instances such ethnic groups are adherents of Christian or Islamic faiths.

Various studies from all parts of the world have reported that cultural factors such as ethnicity and religious beliefs influence the use of maternal health services and need to be taken into consideration for any effective intervention. ${ }^{7-13}$ This approach has been will covered in some parts of south America. ${ }^{10}$ Furthermore, WHO considers the inclusion of approaches that address ethno-religious barriers as good practices that will facilitate the optimal utilization of ANC, natal and post natal maternal health services. ${ }^{12,13}$ Hence, among possible ways to improve pregnancy outcome is by understanding the underlying causes of disparities within a given country or geopolitical region. Religion and ethnicity are part of the fabrics of culture of defined population and has been reported as a pointer to low utilization rate of maternal health services and poor pregnancy outcomes even in developed ${ }^{14-16}$ and developing countries. ${ }^{17-19}$ In general, poor pregnancy outcome has been reported to be common among pregnant women with low use of ANC and delivery services. ${ }^{20,21}$ In Nigeria, the low rate of ANC and delivery was partly due to cultural factors such as ethnicity and religious beliefs ${ }^{22,23}$ and low level of female autonomy which is driven by religion and ethnic beliefs. ${ }^{24-26}$ The role of ANC in averting pregnancy related deaths and other forms of 
poor pregnancy outcomes such as vesico-vaginal fistula was further underscored by WHO in late 2016 that the recommended number of ANC visits should now be at least 8 instead of 4 for optimal pregnancy outcomes. ${ }^{27}$ The implementation of the new recommendation requires an understanding of the cultural setting of a given area in order to develop ethno-religious appropriate communication strategies in order to sensitize communities on the new number of ANC visits expected during pregnancy. The approach further requires the systematic engagement for proactive involvement and participation of the leaders (tribal, religious, traditional, political, etc).${ }^{27}$ Hence, this work intend to understand whether Nigerian women's cultural profile measured by ethnicity and religious beliefs is significantly associated with the frequency of the utilization of ANC and delivery services.

\section{Methods}

Nigeria has an estimated population of 143 million. Women 15-49years and annual number of pregnancies were estimated to be 31.4 million and 8.3 million respectively. ${ }^{4}$ The country has 36 states and a federal capital territory (FCT). The 36 states and FCT were grouped into six geopolitical zones: South-south zone is mainly inhabited by Kalbiri, Ijaw, Ikoi, Itsekiri, and Ibibio; Yoruba in the South west zone as the principal ethnic group; North Central zone consist of Nupe, Ebira, Idoma, Tivs, Igala, Gwari, and Angas; the major tribal groups in the North East are Kanuri, Fulani, Marghi, Babur, Mumuye, and Jukun; the Igbos are the dominant tribe in the South East; while the North west zone are mostly belonging to Hausa and Fulani tribal groups. Islam and Christianity are the dominant religions having followership of about $99 \%$ of Nigerians in the Northern and Southern geopolitical zones respectively. This study is secondary data analysis using the raw data of the Nigerian Demographic and Health Survey (DHS). A two stage stratified cluster design was applied to select and interview 33,385 female participants in the reproductive age group (15-49years) from 286 and 602 for urban and rural areas respectively. ${ }^{4}$ However, only the data of $31,815(95.3 \%)$ were found to be complete and therefore, used in the analysis of this study. Details on sampling, training of interviewers, instruments of data collection and data storage were available online in the Demographic and Health report (DHS). ${ }^{4}$

Religious beliefs of women was coded as 1 for Muslims, code 2 for Christians and Traditional religion as code 3. Muslim women were compared to women of other religion. Ethnicity of women was coded as 1 for Hausa, 2 for Yoruba, 3 for Igbos, 4 for Fulani, 5 for Ijaw/ Izom, 6 for Ibibio, 7 for Tiv, 8 for Kanuri/Baribari, 9 for Ekot, 10 for Igala and 11 for others which comprises of the remaining 364 ethnic groups. ${ }^{4}$ Those belonging to the Hausa ethnic group were compared to other ethnic groups. The research question of this study is: are Nigerian women's cultural profile measured by ethnicity and religious beliefs are significantly associated with the frequency of the antenatal care visits (ANC) and choice of place of delivery? The outcome variables are dichotomous categorical (had four ANC visits/had $<$ four ANC visits; and delivered at home/delivered in hospital). Bivariate Pearson Chi-square statistic and Multivariate logistic regression were conducted at $95 \%$ confidence interval to test the following null hypothesis: $H_{02 \mathrm{~A}}$ : There is no significant statistical association between the religious beliefs of women and their use of MHS as measured by the number of antenatal visits and place of delivery.

a. $\mathrm{Ha}_{2 \mathrm{~A}}:$ There is a significant statistical association between the religious beliefs of women and their use of MHS as measured by the number of antenatal visits and place of delivery. b. $H_{02 \mathrm{~B}}$ : There is no significant statistical association between the ethic affiliation of women and their use of MHS as measured by the number of antenatal visits and place of delivery.

c. $H \mathrm{a}_{2 \mathrm{~B}}$ : There is a significant statistical association between the ethnic affiliation women and their use of MHS as measured by the number of antenatal visits and place of delivery.

Similar analytical approach using DHS data to determine the variables that influence the use of maternity and child services in Nigeria were conducted. ${ }^{28,29}$ The theoretical framework for the study was the Anderson health behaviour model, ${ }^{30,31}$ which consisted of construct on individual characteristics such as ethnicity/tribe and religion that explains differences in the utilization of health services. The study was approved by the Institutional Review Board (IRB) of Walden University, Minneapolis, USA through a communication dated $24^{\text {th }}$ January, 2015 with approval reference number 01-23-150338613. Permission to use the DHS raw data was granted by ORC Macro and ICF International, Calverton Maryland, USA.

\section{Results}

\section{Cultural characteristics of respondents}

The ethnic distribution showed that, out of the 31,985 of women, the Hausas (21.3\%), Igbo's (14.4\%), Yoruba's (13.3\%) and Fulani's $(7.6 \%)$ accounted for $56.6 \%$ of the whole sample. Yoruba women from south west zone of Nigeria have the highest use rate for ANC $(36.8 \%)$, while the Kanuri/Beriberi women of North east zone had the lowest of $14.6 \%$ (Table 1). Islam and Christianity are the dominant religions accounting for $46.8 \%$ and $51.6 \%$ respectively (Figure 1). Moreover, Christians have higher proportion of women that had 4 or more ANC visits (28.2\%) compared to women belonging to Islamic faith (21.6\%). A woman's religious beliefs was found to be statistically associated with the number of ANC visits $\left(\chi^{2}=189.956 \mathrm{df}=2 ; p<.001\right)$. Christian women are more likely to have 4 or more ANC visits than their Muslim counterparts (AOR=1.172; CI 1.158-1.983; $p<.001)$ (Table 2). Religion has significant statistical association with the place of delivery $\left(\chi^{2}=2542.37 \mathrm{df}=2 ; p<.001\right)$ (Table 3 ). Christian women are mores 5 times more likely to deliver in a health facility than their Muslim counterparts (UOR $=5.181$; CI 4.844-5.542). However, after adjusting for confounding, this association was no longer statistically significant (AOR=1.308; CI 0.987-1.733; $p>.05)$ (Table 3).

Table I The frequency of antenatal care visits by respondent's ethnic affiliation.

\begin{tabular}{cccc}
$\begin{array}{l}\text { Independent } \\
\text { Variable }\end{array}$ & $\begin{array}{c}\text { Proportion of } \\
\text { Samples (\%) }\end{array}$ & $\begin{array}{c}\text { Number of ANC Visits } \\
<4\end{array}$ & $\mathbf{4}$ \\
\hline Ethnicity & & & 16.6 \\
\hline Hausa & 21.3 & 83.4 & 36.8 \\
Yoruba & 14.4 & 63.2 & 26.9 \\
Igbo & 13.3 & 73.1 & 14.7 \\
Fulani & 7.6 & 85.3 & 19.6 \\
ljaw/lzom & 3.6 & 80.4 & 27.3 \\
Ibibio & 2.1 & 72.7 & 19 \\
TIV & 2.8 & 81 & 14.6 \\
Kanuri/baribari & 2.6 & 85.4 & 31.5 \\
Ekot & 1.8 & 68.5 & 29.2 \\
Igala & 1.6 & 70.8 & 28.4 \\
\hline Others & 29.1 & 71.6 & \\
\hline
\end{tabular}




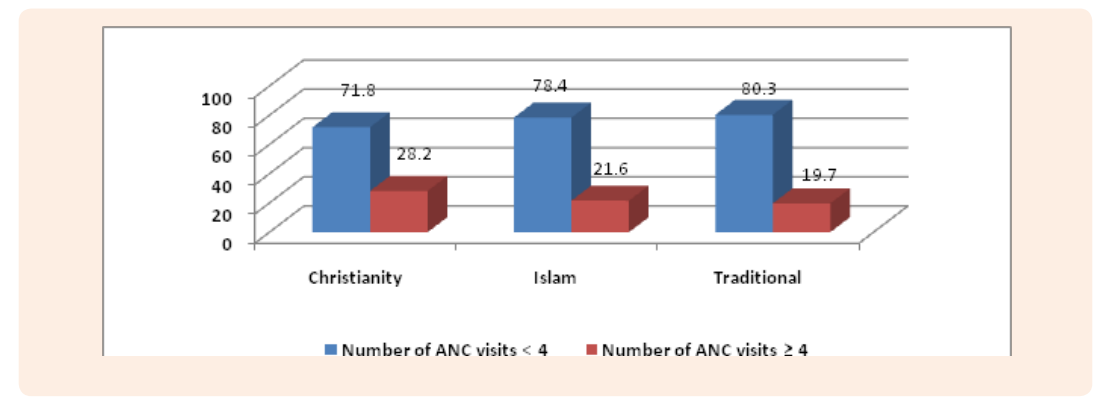

Figure I Proportion of ANC visits made by religious beliefs of women.

Note: Variables adjusted in the model: education, income, religion, geopolitical zone of residence, availability of skilled health worker and place of domicile.

Table 2 Association between woman's religious beliefs and the number of antenatal visits.

\begin{tabular}{|c|c|c|c|c|c|c|c|c|c|c|}
\hline \multirow[b]{3}{*}{ Religion } & \multirow{2}{*}{\multicolumn{2}{|c|}{$\begin{array}{l}\text { ANC } \\
\text { Visits } \\
\text { < Visits } \geq 4 \text { Visits }\end{array}$}} & \multirow{2}{*}{$\begin{array}{c}\text { Bivariate Analysis } \\
\text { Pearson's Chi- } \\
\text { square }\end{array}$} & \multicolumn{7}{|c|}{$\begin{array}{l}\text { Multivariate Logistic Regression } \\
\text { Analysis }\end{array}$} \\
\hline & & & & UOR & $95 \%$ & AOR & AOR & P Values & $95 \%$ & AOR \\
\hline & & & & \multicolumn{4}{|c|}{ Lower limit Upper limit } & \multicolumn{3}{|c|}{ Lower Limit Upper Limit } \\
\hline Islam & 11680 & 3218 & $0.001 *$ & 1.000 & & & 1.000 & & & \\
\hline Christianity & 11776 & 4628 & & 1.426 & 1.354 & 1.502 & 1.172 & $0.001 *$ & 1.158 & 1.983 \\
\hline Traditional & 412 & 101 & & 0.89 & 0.713 & 1.11 & 1.202 & 0.231 & 0.889 & 1.624 \\
\hline
\end{tabular}

*p is significant at the 0.05 level.

Note: Variables adjusted in the model: income, parity, education, age and distance.

Table 3 Association between women's religious beliefs and the place of delivery.

\begin{tabular}{|c|c|c|c|c|c|c|c|c|c|c|}
\hline \multirow{4}{*}{$\begin{array}{c}\text { Religion } \\
\text { Islam }\end{array}$} & \multicolumn{2}{|c|}{ Place of Delivery } & \multirow{3}{*}{$\begin{array}{c}\text { Bivariate Analysis } \\
\text { Pearson's Chi-square }\end{array}$} & \multicolumn{7}{|c|}{ Multivariate Logistic Regression Analysis } \\
\hline & \multirow{3}{*}{$\begin{array}{c}\text { Home } \\
8002 \\
\end{array}$} & \multirow{3}{*}{$\begin{array}{c}\text { Facility } \\
1909\end{array}$} & & \multirow[t]{2}{*}{ UOR } & \multicolumn{2}{|c|}{ 95\% Cl for UOR } & \multirow{2}{*}{ AOR } & \multirow{2}{*}{$P$ value } & \multicolumn{2}{|c|}{$95 \% \mathrm{Cl}$ for AOR } \\
\hline & & & & & wer Lin & per $\mathrm{Li}$ & & & Lower Lir & per Limit \\
\hline & & & $0.001 *$ & 1.000 & & & 1.000 & & & \\
\hline Christianity & 3397 & 4199 & & 5.181 & 4.844 & 5.542 & 1.308 & 0.611 & 0.987 & 1.733 \\
\hline Tradition & 296 & 43 & & 0.609 & 0.441 & 0.842 & 0.492 & 0.932 & 0.198 & 1.219 \\
\hline
\end{tabular}

$*_{p}$ is significant at the 0.05 level.

Note: Variables adjusted in the model: income, parity, education, age, availability of skilled health worker and distance.

Ethnicity showed a statistically significant variation $\left(\chi^{2}=900.570\right.$; $\mathrm{df}=10 ; p<.001)$ within and between the geopolitical zones of northern and southern Nigeria (Table 4). For instance, the highest proportion of women who had four or more ANC visits in order of magnitude were the Yoruba's (South west), Ekot (South-south), Igala (North central), Ibibio (South-south) and Igbos (South east). The lowest belonged to Kanuri/Baribari (north east), Hausa (North west) and Tiv (North central). The Fulani's of the North east and North west zones had higher proportion of women who have made four or more ANC visits compared to ethnic groups of the south such as Ijaw/Izom (South-south) and approximate what is observed among the Igbo's of the south east zone (Table 4). Compared to the Hausa's (North West), the odds for a Yoruba woman have adequate number of ANC is three fold (UOR=2.923; CI 2.678-3.19), followed by Ekot $(\mathrm{UOR}=2.31$; CI 1.915-2.787), Igala $(\mathrm{OR}=2.065$; CI 1.69-2.521) and Ibibio (UOR=1.88; CI 1.573-2.266) (Table 4). Women belonging to the Hausa ethnic group (Northern Nigeria) were 1.2 times less likely to achieve the 4 recommended number of ANC visits compared to Yoruba women (Southern Nigeria) even when covariates were controlled $(\mathrm{AOR}=1.272$; CI 1.048-1.543; $p<.05)$ (Table 4). There appeared to be an association between ethnicity and place of delivery $\left(\chi^{2}=5329.865 ; \mathrm{df}=10 ; p<0.001\right)$ (Table 5). The highest proportion $(\geq 70 \%)$ of women who delivered in a health facility in order of magnitude were the Yoruba's in the South west (78.7\%), Igala in the North central (75.9\%), and Igbos in the South east (73.8\%). The lowest belonged to Fulani in the north east (7.9\%), Kanuri/Beriberi, north east $(8.6 \%)$, and Hausa in the North West $(9.6 \%)$. The odds of a Yoruba woman (South west) giving birth in a health facility is 35 folds compared to a Hausa woman $(\mathrm{UOR}=34.817$; CI 30.233-40.097), followed by Igala in the North central (UOR $=29.723$; CI 21.509 41.076) and Igbo in the south east ( $\mathrm{UOR}=26.562$; CI 23.035-30.63) (Table 5). This association remained statistically significant even after controlling for confounding. 
Table 4 Association between the tribal/ethnic affiliation of women and the number of antenatal visits.

\begin{tabular}{|c|c|c|c|c|c|c|c|c|c|c|}
\hline \multirow[t]{3}{*}{ Ethnicity } & \multicolumn{2}{|c|}{ ANCVisits } & \multirow{3}{*}{$\begin{array}{l}\text { Bivariate Analysis } \\
\text { Pearson Chi-square }\end{array}$} & \multicolumn{7}{|c|}{ Multivariate Logistic Regression Analysis } \\
\hline & \multirow[t]{2}{*}{$<4$ visits } & \multirow[t]{2}{*}{$>4$ visits } & & \multicolumn{3}{|c|}{ UOR $95 \% \mathrm{CI}$ for UOR } & \multirow[t]{2}{*}{ AOR } & \multicolumn{3}{|c|}{$P$ values $95 \% \mathrm{CI}$ for $\mathrm{AOR}$} \\
\hline & & & & & Lower Limit & Upper Limit & & & Lower Limit & Upper Limit \\
\hline Hausa & 5670 & 1130 & $0.001 *$ & 1.000 & & & 1.000 & & & \\
\hline Yoruba & 2908 & 1694 & & 2.923 & 2.678 & 3.19 & 1.272 & $0.015^{*}$ & 1.048 & $\mathrm{I} .143$ \\
\hline Igbo & 3119 & 1147 & & 1.845 & 1.681 & 2.005 & 0.889 & 0.346 & 0.696 & 1.135 \\
\hline Fulani & 2061 & 355 & & 0.864 & 0.759 & 0.984 & 0.727 & 0.121 & 0.62 & 1.853 \\
\hline ljaw/ & 913 & 223 & & 1.226 & 1.045 & 1.438 & 0.54 & $0.011^{*}$ & 0.417 & 0.699 \\
\hline Ibibio & $48 I$ & 181 & & 1.888 & 1.573 & 2.266 & 0.964 & 0.808 & 0.717 & 1.296 \\
\hline TIV & 723 & 170 & & 1.18 & 0.987 & $\mathrm{I} .4 \mathrm{II}$ & 0.685 & 0.441 & 0.532 & 1.884 \\
\hline Kanuri/Beriberi & 707 & $|2|$ & & 0.859 & 0.701 & 1.062 & 0.545 & 0.211 & 0.429 & 1.692 \\
\hline Ekot & 391 & 180 & & 2.31 & 1.915 & 2.787 & 1.079 & 0.626 & 0.794 & 1.467 \\
\hline Igala & 367 & $|5|$ & & 2.065 & 1.69 & 2.521 & 1.186 & 0.25 & 0.887 & 1.586 \\
\hline Others & 6657 & 2636 & & 1.987 & 1.837 & 2.148 & 1.191 & $0.011 *$ & $1.04 \mid$ & 1.163 \\
\hline
\end{tabular}

*p is significant at the 0.05 level.

Note: Variables adjusted in the model: education, income, autonomy, religion, geopolitical zone of residence, and place of domicile.

Table 5 Association between the tribal/ethnic affiliation of women and the place of delivery.

\begin{tabular}{|c|c|c|c|c|c|c|c|c|c|c|}
\hline \multirow[t]{3}{*}{ Ethnicity } & \multicolumn{2}{|c|}{$\begin{array}{l}\text { Place of } \\
\text { Delivery }\end{array}$} & \multirow{3}{*}{$\begin{array}{l}\text { Bivariate Analysis } \\
\text { Pearson's Chi-square }\end{array}$} & \multicolumn{7}{|c|}{ Multivariate Logistic Regression Analysis } \\
\hline & \multirow[t]{2}{*}{ Home } & \multirow[t]{2}{*}{ Facility } & & \multirow[t]{2}{*}{ UOR } & \multicolumn{2}{|c|}{ 95\% Cl for UOR } & & \multirow[t]{2}{*}{$\begin{array}{l}\mathbf{P} \\
\text { values }\end{array}$} & \multicolumn{2}{|c|}{ 95\% CI for AOR } \\
\hline & & & & & Lower Limit & Upper Limit & & & Lower Limit & Upper Limit \\
\hline Hausa & 4377 & 464 & $0.001 *$ & 1.000 & & & 1.000 & & & \\
\hline Yoruba & 453 & 1672 & & 34.817 & 30.233 & 40.097 & 2.318 & $0.002 *$ & 1.36 & 3.954 \\
\hline Igbo & 467 & 1315 & & 26.562 & 23.035 & 30.63 & 2.13 & $0.037^{*}$ & 1.046 & 4.339 \\
\hline Fulani & 1573 & 135 & & 0.81 & 0.663 & 0.989 & 1.473 & 0.197 & 0.818 & 2.654 \\
\hline ljaw/Izom & 416 & 129 & & 2.925 & 2.349 & 3.643 & 0.326 & 0.088 & 0.155 & 0.686 \\
\hline Ibibio & 146 & 135 & & 8.722 & 6.774 & 11.232 & 0.703 & 0.37 & 0.325 & $\mathrm{I} .52 \mathrm{I}$ \\
\hline TIV & 270 & 218 & & 7.616 & 6.22 & 9.326 & 2.595 & $0.03 I^{*}$ & 1.092 & 6.17 \\
\hline Kanuri/Beriberi & 501 & 47 & & 0.885 & 0.647 & 1.211 & 0.977 & 0.956 & 0.425 & 2.245 \\
\hline Ekot & 246 & 145 & & 5.56 & 4.434 & 6.973 & 0.49 & 0.053 & 0.238 & 1.008 \\
\hline Igala & 53 & 167 & & 29.723 & 21.509 & 41.076 & 9.902 & $0.001 *$ & 3.913 & 25.062 \\
\hline Others & 3273 & 1747 & & 5.035 & 4.502 & 5.631 & 1.082 & 0.72 & 0.703 & 1.665 \\
\hline
\end{tabular}

*p is significant at the 0.05 level.

\section{Discussions on findings}

In this study, ethnicity and to a lesser extent religion were found to influence the use of MHS with women belonging to HausaFulani and kanuri/Bari-Bari ethnic groups and Muslims less likely to achieve the recommended number of ANC visits and deliver in a health facility. Plausible explanations include lower levels of female literacy, ${ }^{4-33}$ empowerment, ${ }^{34}$ and autonomy ${ }^{23}$ among the HausaFulani and kanuri/Bari-Bari women compared to even women in belonging to other ethnic groups of northern Nigeria such as Igala and the Tivs. This finding was consistent with other studies where it has been documented that ethno-religious belief influenced the use of MHS, ${ }^{32-36}$ Female autonomy was further reported to be low among the Hausa-Fulani and kanuri/Bari-Bari ethic groups of Northern Nigeria due to adherence to aged long stereotyping as to what is an ideal woman that was based on ethnic and religious norms, beliefs, traditions and practices which was reported to result in low use of MHS and higher incidence of poor pregnancy outcomes in developing ${ }^{29-39}$ and developed countries. ${ }^{15-40}$ However, it should be noted that failure to attain the recommended number of ANC visits and to deliver in a health facility will invariably defeat the basic objective of Maternal health Services such as promoting the health 
of women through health education, counseling, vaccination, family planning, chemo-prophylaxis against malaria, minerals, vitamins and nutritional supplements (iron, and folic acid, screening and early detection of high-risk pregnancies. The low utilization of ANC and delivery services among the Muslim Hausa-Fulani and kanuri/ Bari-Bari women as observed in this study is consistent with other reports that indicated that the odds for a Muslim woman to achieve the recommended number of ANC visits and or deliver in modern health facility is very low compared to their Christian counterparts residing in the same geographical area and belong to same socio-economic level. ${ }^{37}$

However, previous reports noted that the effect of ethnicity and religious beliefs on the use of MHS was inconsistently after controlling for educational attainment and the level of income. For instance, although in this study, the Yoruba ethnic group was found to have the highest proportion of women who had the recommended number of ANC visit and delivery in a health facility. However, Adelaja ${ }^{41}$ reported that about $70 \%$ of Christian Yoruba's had delivered at home despite the fact that majority of them are literate, employed and have higher autonomy compared to the Muslim Hausa-Fulani and kanuri/BariBari ethnic groups. ${ }^{4,34}$ Religious and ethnic beliefs and practices may affect the rate of utilization of MHS as exemplifies by a study among the Hausa Fulani of North western Nigeria that women preferred to deliver in homes because they consider the lithotomy position and being supervised by not a close relative as embarrassing. ${ }^{42}$ Similar findings were reported from some countries in Southern Africa, ${ }^{43}$ West Africa, ${ }^{44}$ and South East Asia, ${ }^{45,46}$ Hence, the observed ethno-religious influence on the use of MHS underscored the need for systematic and consistent pro-active involvement and participation of community, religious and tribal leaders in the planning, implementation, and monitoring of population based MHS in order to enhance ownership, commitment and oversight functions.

\section{Conclusion and recommendations}

\section{The findings of my study have demonstrated that:}

a. Ethnicity and to a lesser extent religion were found to influence the use of MHS with women belonging to Hausa-Fulani and kanuri/Bari-Bari ethnic groups have the lowest proportion of women who had achieved the recommended number of ANC visits and or delivered in a health facility;

Women belonging to Islamic faith were less likely to make the recommended number of ANC visits and or deliver in health facility;

b. The lower utilization rate for ANC and delivery services was lower among Hausa-Fulani and kanuri/Bari-Bari ethnic groups even after controlling for confounders such as education, income, place of domicile, availability of skilled health workers, and distance;

c. These findings have underscored the need for systematic and consistent pro-active involvement and participation of community, religious and tribal leaders in the planning, implementation, and monitoring of population based MHS in order to enhance ownership, commitment and oversight functions.

\section{Strengths and weaknesses of this study}

The large sample size $(33,385)$ and the recruitment of participants across various strata using stratified two stage cluster sampling had strengthened the external validity and generalizability of the findings of this study ${ }^{47}$ However, the DHS being a cross-sectional study design does only demonstrate an existing association (not causality) between ethnicity and religious beliefs and the use of ANC and delivery services.

\section{Acknowledgement}

The author extends his sincere thanks to Dr. Chinaro Kennedy; Dr. Hebatullah Tawfik and Dr. Daniel Okenu all of Walden University, USA, for their immense contribution in all aspect of this work. I would also like to thank and acknowledge ORC Macro and ICF International Calverton Maryland, USA for granting me the permission to use the DHS dataset.

\section{Conflicts of interest}

None.

\section{Funding}

None.

\section{References}

1. World Health Statistics. Switzerland: World Health Organization; 2017. p. $1-116$.

2. Trends in Maternal Mortality: 1990 to 2015, Estimates by WHO, UNICEF, UNFPA, World Bank Group and the United Nations Population Division. Switzerland: World Health Organization; 2017. p. 1-92.

3. World Health Statistics. Switzerland: World Health Organization; 2013. p. $1-172$.

4. National Population Commission (Nigeria), ICF Macro Nigeria Demographic and Health Survey 2008. USA. 2009. p. 1-661.

5. Maternal death surveillance and response: Technical guidance, Information for action to prevent maternal death. Switzerland: World Health Organization; 2013. p .1-128.

6. Primary Health Care in Nigeria: 30years after Alma-Ata, The Nigerian Health Review, Health Reform Foundation of Nigeria, Nigeria: Mmm-nat Educational Window Consultant Ltd. 2007.

7. Camacho AV, Castro MD, Kaufman R. Cultural aspects related to the health of Andean women in Latin America: A key issue for progress toward the attainment of the Millennium Development Goals. Int $J$ Gynaecol Obstet. 2006;94(3):357-363.

8. Mackian S, Bedri N, Lovel H. Up the garden path and over the edge: where might health-seeking behaviour take us?. Health Policy Plan. 2004;19(3):137-146.

9. Miller T. Shifting boundaries: Exploring the influence of cultural traditions and religious beliefs of Bangladeshi women on prenatal interactions. Women's Studies International Forum. 1995;18(3):299-309.

10. Simwaka BN, Theobald S, Amekudzi YP, et al. Meeting millennium development goals 3 and 5. BMJ. 2005;331(7519):708-709.

11. Working with individuals, families and communities to improve maternal and neonatal Health. World Health Organization, Switzerland. 2003;1-63.

12. World Health Report. Make every mother and child count. Switzerland: World Health Organization; 2005.

13. Maternal mortality in 2005: Estimates developed by WHO, UNICEF, UNFPA, and the World Bank. World Health Organization, Switzerland. 2007; $1-48$.

14. Jomeen J, Redshaw M. Ethnic minority women's experience of maternity services in England. Ethn Health. 2013;18(3):280-296. 
15. Lyons SM, O'Keeffe FM, Clarke AT, et al. Cultural diversity in the Dublin maternity services: the experiences of maternity service providers when caring for ethnic minority women. Ethn Health. 2008;13(3):261-276.

16. Phillimore J. Delivering maternity services in an era of super diversity: the challenges of novelty and newness. Journal of Ethnic and Racial Studies. 2015;38(4):568-582.

17. Evans EC. A review of cultural influence on maternal mortality in the developing world. Midwifery. 2013;29(5):490-496.

18. Mselle LT, Moland KM, Mvungi A, et al. Why give birth in health facility? Users' and providers' accounts of poor quality of birth care in Tanzania. BMC Health Serv Res. 2013;13:174.

19. Owais A, Faruque AG, Das SK, et al. Maternal and Antenatal Risk Factors for Stillbirths and Neonatal Mortality in Rural Bangladesh: A Case-Control Study. PLoS One. 2013;8(11):e80164.

20. Maternal health, Switzerland: World Health Organization. 2015.

21. World Health Organization, UNICEF, UNFPA, The World Bank Trends in Maternal Mortality: 1990 to 2008. Switzerland. 2010;1-52.

22. Coast E, Jones E, Portela A, et al. Maternity Care Services and Culture: A Systematic Global Mapping of Interventions. PLoS One. 2014;9(9):e108130.

23. Titaley CR, Hunter CL, Dibley MJ, et al. Why do some women still prefe traditional birth attendants and home delivery?: A qualitative study on delivery care services in West Java Province, Indonesia. BMC Pregnancy Childbirth. 2010;10:43

24. Umar AS. Women Autonomy and the use of Antenatal and Delivery Services in Nigeria. MOJ Public Health. 2017;6(2):00161.

25. Adamu YM, Salihu HM. Barriers to the use of antenatal and obstetric care services in rural Kano, Nigeria. J Obstet Gynaecol. 2002;22(6):600-603.

26. Idris SH, Gwarzo UMD, Shebu AU. Determinants of place of delivery among women in semi urban settlement in Zaria, Northern Nigeria. Annals of African Medicine. 2006;5(2):68-72.

27. WHO recommendations on antenatal care for a positive pregnancy experience, World Health Organization, Switzerland. 2016;1-172.

28. Antai D. Faith and child survival: the role of religion in childhood immunization in Nigeria. J Biosoc Sci. 2009;41(1):57-76.

29. Fapohunda B, Orobaron N. Factors influencing the selection of delivery with no one present in Northern Nigeria: implications for policy and programs. Int J Women's Health. 2014;6:171-183.

30. Andersen RM. Revisiting the behavioral model and access to medical care: does it matter?. J Health Soc Behav. 1995;36(1):1-10.

31. Andersen RM, Newman JF. Societal and individual determinants of medical care utilization in the United States. Milbank Mem Fund Q Health Soc. 2005;51(1):95-124.
32. Akinbi JO, Akinbi YA. Gender Disparity in Enrolment into Basic Formal Education in Nigeria: Implications for National Development. Afr Res Rev. 2015;9(3):11-23.

33. Umar AS. Does Female Education explain the disparity in the use of Antenatal and Natal Services in Nigeria? Evidence from Demographic and Health Survey Data. Afr Health Sci. 2017;17(2):391-399.

34. Umar AS. Female Economic Empowerment as a Significant Factor of Social Exclusion on the use of Antenatal and Natal Services in Nigeria. MOJ Women 's' Health. 2017;5(2):00118.

35. Nmadu G, Avidime S, Oguntunde O, et al. Girl Child Education: Rising to the challenge. Afr J Reprod Health. 2010;14(3):107-112.

36. Okafor VE, Arinze FO. Gender accessibility and equality in education: The implication to manpower in Nigeria. Afr Res Rev. 2012;6(3):284-290.

37. Babalola S, Fatusi A. Determinants of use of maternal health services in Nigeria-looking beyond individual and household factors. BMC Pregnancy Childbirth. 2009;9:43.

38. Doctor HV, Bairagi R, Findley SE, et al. Northern Nigeria, Maternal, Newborn, and Child Health Program: Selected analysis from population based baseline study. The Open Demography Journal. 2011;4:11-21.

39. Fawole AO, Shah A, Fabanwo AO, et al. Predictors of maternal mortality in institutional deliveries in Nigeria. Afr Health Sci. 2012;12(1): 32-40.

40. Handerson J, Gao H, Redshaw M. Experiencing maternity care: the care received and perceptions of women from different ethnic groups. BMC Pregnancy Childbirth. 2013;13:196.

41. Adelaja LM. A survey of home delivery and newborn care practices among women in suburban area of South western Nigeria. ISRN Obstet Gynecol. 2011:983542.

42. Ityavyar DA. A traditional midwife practice in Sokoto state, Nigeria. Soc Sci Med. 1984;18(6):497-501.

43. Wabiri N, Chersich M, Zuma K, et al. Equity in maternal health in South Africa: Analysis of health service Access and health Status in a National Household Survey. PLoS One. 2013;8(9):e73864.

44. Ganle JK, Parker M, Fitzpatrick R, et al. Inequities in accessibility to and utilisation of maternal health services in Ghana after user-fee exemption: a descriptive study. Int J Equity Health. 2014;13:89.

45. Anwar I, Nababan HY, Mostari S, et al. Trends and Inequities in Use of Maternal Health Care Services in Bangladesh 1991- 2011. PLoS One. 2015;10(3):e0120309.

46. Saxena D, Vangani R, Mavalankar DV, et al. Inequity in maternal health care service utilization in Gujarat: analyses of district level health survey data. Glob Health Action. 2013;6:1-9.

47. Szklo M, Nieto FJ. Understanding a Lack of Validity: Bias in Epidemiology: Beyond the basics. $3^{\text {rd }}$ edn. UK: Jones and Bartlett; 2014 